\title{
La gran burrada
}

Keywords: burros; équidos; fiestas populares; espectáculos con animales

Las fiestas patronales recorren la geografía española durante todo el año, pero suelen ser especialmente frecuentes en verano, poniendo el acento en celebraciones en las que no suelen faltar los animales a los que se les trata "como lo que son, animales".

Este "no-razonamiento", afirmación pronunciada en tono de seguridad apodíctica, es lo que -si se pregunta a los vecinos o a las autoridades locales, por qué se somete a animales a actos en los que, como mínimo, se les produce estrés-, se recibe como respuesta: se les trata, como lo que son, animales. Con esta aparente lógica, cargada de ignorancia y de insensibilidad, se celebran en nuestro suelo algunos actos que, en el propio título con el que se anuncian, llevan el calificativo. Me refiero en concreto a "La gran burrada" de un pueblo de Huesca, consistente en la suelta de unos burros en un recinto cerrado, para que los vecinos los monten y no precisamente de uno en uno. Al parecer, el imaginativo festejo ha venido a sustituir, en los últimos años de crisis, a la suelta de vaquillas ya que resultaban muy caras, pues dichos festejos con vacas, de los que tampoco alabo el gusto popular, sí están regulados con mayor precisión y exigencia, en cuanto al transporte de los animales, la presencia de sanitarios y el tiempo en que se les puede tener echando carreras enloquecidas por las calles del pueblo.

Sobre esta particular celebración, que viene levantando la protesta de colectivos animalistas, cada vez más insistentes, las fuentes locales se encogen de hombros o responden con cazurrería que los burros son animales de carga y están acostumbrados a soportar peso, por lo que, el que los monten a pelo, tres y cuatro vecinos al mismo tiempo, resulta incluso civilizado. Por la megafonía del recinto, tratando de poner la venda antes que la herida, se advertía que no se les hiciera daño. Es claro que sólo la algarabía que se produce para montar a los burros, para sujetarlos como sea y para acabar en el suelo, si el pobre animal consigue desembarazarse de la carga, es el núcleo de una diversión en la que el único que no se divierte es el animal. Un burro no ha nacido para cargar peso, ni para servir de forma humillante como diversión a gente desocupada, aunque sea un sólo día al año. Revela una carencia grave de conocimiento de la naturaleza de un burro, el usarlos para semejante "burrada". Habría que averiguar, si en la Biblioteca Municipal existe algún ejemplar de "Platero y yo" -del Premio Nobel Juan Ramón Jiménez-, y cúantas salidas ha registrado dicho libro en los últimos años.

Por lo demás, en Aragón, como el resto de Comunidades Autónomas, está vigente la legislación de protección animal [1], por la que se dispone la prohibición en los espectáculos con animales del trato cruel, inadecuado o antinatural para proteger el bienestar de los animales. Es más, el articulado dice expresamente que no tratándose de corridas de toros (sic), no se permitirán prácticas o espectáculos que puedan emplearse como excusa para causar daños a los animales. Es claro que la falta de claridad en la redacción ampara una interpretación laxa de la misma, por la que se pueda argumentar que, en el espectáculo en cuestión, no se busca directamente dañar a los animales ni darles un trato antinatural. Lo "natural" en el caso de los burros sería (lo que parece sosegar la conciencia de los organizadores y ampararlos en la legalidad vigente), acarrear peso y soportar los tirones y el ruido de la gente dentro de un recinto en el que no pueden salir, como destino "natural" de su especie.

La UE está promoviendo un gran debate legislativo para mejorar la protección de los équidos, entre los que se incluyen burros y mulas, además de los caballos. Hay muchas deficiencias en la actual legislación de los Estados Miembros que deben ser corregidas, es preciso que se llegue a un consenso amplio sobre cómo se les debe proteger mejor, de acuerdo con los conocimientos que la ciencia ha adquirido sobre su 
naturaleza y necesidades, que, como mínimo, los engloba dentro de la categoría de "seres sintientes", a tenor del art. 13 del TFUE [2] . Se abre un horizonte para que, en muchos países, incluido el nuestro, los burros dejen de ser objeto de menosprecio, de uso abusivo y de maltrato [3]. No sólo depende de la ley, es cierto, depende mucho también de la sensibilidad social, pero estoy persuadida de que la sociedad rechaza cada vez más mayoritariamente el abuso de los animales en espectáculos y dicho rechazo es un gran fuerza, callada aparentemente, que se está abriendo paso y no hay vuelta atrás.

Uno de los libros que presidió mis lecturas de infancia, es "Memoires d'un âne" (=Las memorias de un burro), escrito por la Condesa de Ségur [4]. Es una pequeña joya de la literatura, que ahora cuesta encontrar, incluso rebuscando entre las librerías de viejo que rodean la Sorbonne. Describe la historia de un pollino llamado Cadichon que sufre mil peripecias, hambre, malos tratos y abandono hasta que los niños de una casa rural lo recogen, para hacerlo servir como tiro de una pequeña calesa. Ése es el giro de su vida y el comienzo de un proceso de sensibilización, no sólo de los niños a los que el conocimiento del animal les hace rechazar engancharlo como animal de tiro, sino incluso de los vecinos del pueblo que habían asistido indiferentes a las sevicias que, anteriormente y a vista de todo el pueblo, había sido objeto el animal.

Se trata claramente de un ejemplo de literatura de trasfondo moral, propia del XIX, que refleja las costumbres y la visión de una parte de la sociedad francesa, que ya había movilizado en el S. XVIII a grandes escritores como Voltaire en defensa de los animales, pero que muestra también que la consideración y el respeto por los animales, no sólo es cuestión de leyes, sino también de actitudes y de hábitos sociales, que en la sociedad francesa siempre han sido un signo distintivo en favor de los animales. Me pregunto si en el siglo XXI, aquí en España, aún tenemos que divertirnos a costa de los animales.

[1] Ley 11/2003 de 19 de marzo, de Protección Animal en la Comunidad Autònoma de Aragón, que dispone en el apartado VIII: "La Ley establece igualmente las limitaciones y prohibiciones necesarias para evitar en un espectáculo con animales el trato cruel, inadecuado o antinatural para con los animales, protegiéndose así tanto el bienestar de los animales como a los propios espectadores.... se establecen reglas y limitaciones que tratan de proteger al animal cuando las prácticas que pueden producirse no tengan conexión con la tradicionales 'fiesta de los toros', sino que más bien ello pueda emplearse como excusa para causar daños a los animales."

[2] Art. 13 del TFUE, llamado Tratado de Lisboa (http://www.boe.es/doue/2010/083/Z00047-00199.pdf), donde se impone a los Estados Miembros la obligación de tratar a los animales como "seres sintientes" en la legislación interna de cada uno de los Estados Miembros, particularmente en materia de agricultura, ganadería, experimentación y espectáculos. Vid. Giménez-Candela, T., Seres sintientes; Los cocodrilos también lloran.

[3] Vid. la noticia que publicamos en el Boletín legislativo de este mes, referente a la paliza propinada al burrito "Capitán", presuntamente por unos niños de un colegio de Almería, de la que el joven pollino se recupera lentamente.

[4] Comtesse de Ségur, Les Mémoires d'un âne (Paris 1965. Ed. Jean-Jacques Pauvert. édition ilustrée de 75 vignettes). El libro se editó por vez primera en 1860, en una colección de la Editorial Hachette denominada "Bibliothèque rose ilustrée". Desde entonces, se han hecho ediciones privadas -como la que cito- y alguna edición de conjunto de las obras de la escritora, como la que apareció en 1990, "Oeuvres de la Comtesse de Ségur" (Paris 1990). 